\title{
Influence of gamma radiation on microshear bond strength and nanoleakage of nanofilled restoratives in $\mathrm{Er}, \mathrm{Cr}$ :YSGG laser-prepared cavities
}

\author{
Engy Fahmy Abaza ${ }^{1}$, Ahmed Abbas Zaki ${ }^{2}$, Haytham Samir Moharram², \\ Amal Alaa El Din El Batouti ${ }^{1}$, Asmaa Aly Yassen ${ }^{3}$
}

Correspondence: Dr. Engy Fahmy Abaza

Email: engy.abaza@live.com

\author{
'Department of Health Radiation Research, National \\ Centre for Radiation Research and Technology, Cairo, \\ Egypt, \\ ${ }^{2}$ Department of Medical Laser Applications, National \\ Institution of Laser Enhanced Sciences, Cairo \\ University, Cairo, Egypt, \\ ${ }^{3}$ Conservative Dentistry Department, Faculty of \\ Dentistry, Cairo University, British University in Egypt, \\ Cairo, Egypt
}

\section{ABSTRACT}

Objective: To evaluate the effect of gamma radiation on microshear bond strength and nanoleakage of nanofilled restoratives in laser-prepared cavities. Materials and Methods: Twenty-eight flat buccal dentin surfaces were prepared for microshear bond strength test. Er, Cr:YSGG laser was used to prepare another 28 Class V cavities on the buccal surfaces of the molars. All teeth were divided into four groups; $1^{\text {st }}$ group: Application of Filtek Z350 nanocomposite material, $2^{\text {nd }}$ group: As the $1^{\text {st }}$ group and then exposure to gamma radiation, $3^{\text {rd }}$ group: Application of Ketac $\mathrm{N} 100$ nanoglass ionomer, and the $4^{\text {th }}$ group: As the $3^{\text {rd }}$ group and then gamma irradiated. The bond strength test was performed after storage in artificial saliva for $24 \mathrm{~h}$. For the nanoleakage test, teeth were submerged in a solution of ammoniacal silver nitrate, sectioned, and then examined under a scanning electron microscope. The collected data were statistically analyzed. Results: Nanocomposite showed higher bond strength values than nanoglass ionomer. Despite the fact that gamma radiation did not decrease nanocomposite bond strength, it decreased nanoglass ionomer bond strength. Nanoglass ionomer-restored cavities showed higher silver ion penetration than nanocomposite in both control and gamma-irradiated groups. Conclusion: Gamma radiation has no effect on bond strength and nanoleakage of nanocomposite so that it can be placed before radiotherapy. On the other hand, the bond strength of nanoglass ionomer was adversely affected by gamma radiation.

Key words: Bond strength, Er, Cr:YSGG laser, gamma radiation, nanoglass ionomer, nanocomposite, nanoleakage

\section{INTRODUCTION}

The vital line of treatment for oral cancer patients is the radiotherapy with a dose ranging between 40 and 70 Gy causing side effects to the adjacent healthy tissues. ${ }^{[1]}$ This irradiation may affect their

\begin{tabular}{|l|l|}
\hline \multicolumn{2}{|c|}{ Access this article online } \\
\hline Quick Response Code: \\
\hline
\end{tabular}

restored teeth. Even with the great advancements in the field of dental restorations, no enough data are available on the effect of radiotherapy on them.

This is an open access journal, and articles are distributed under the terms of the Creative Commons Attribution-NonCommercial-ShareAlike 4.0 License, which allows others to remix, tweak, and build upon the work non-commercially, as long as appropriate credit is given and the new creations are licensed under the identical terms.

For reprints contact: reprints@medknow.com

How to cite this article: Abaza EF, Zaki AA, Moharram HS, El Din El Batouti AA, Yassen AA. Influence of gamma radiation on microshear bond strength and nanoleakage of nanofilled restoratives in Er, Cr:YSGG laser-prepared cavities. Eur J Dent 2018;12:338-43.

DOI: 10.4103/ejd.ejd_305_17 
The high filler content and reduced particle size of nanofilled restorative materials improve their mechanical and esthetic behavior. ${ }^{[2]}$ Simultaneously, as an efficient alternative for conservative cavity preparation, Er, Cr:YSGG laser has been introduced. Its high water and hydroxyapatite absorption lead to selective removal of carious tissue. ${ }^{[3]}$

The degree of success of the dental restoration is mainly determined by the bond strength and the marginal adaptation. ${ }^{[4]}$ The primacy of microshear bond strength test is obtaining more than one specimen from a single tooth. ${ }^{[5]}$

Nanoleakage occurs at the bottom of the hybrid layer where dentinal and oral fluid can slowly invade the interface causing degradation of the bonding system. ${ }^{[6]}$ Numerous researchers have been performed to determine the marginal quality of resin composite fillings in cavities prepared by erbium laser. ${ }^{[7,8]}$ However, evaluating gamma radiation effect on laser-prepared cavities restored with nanorestorative materials is deficient.

Thus, this study is aimed at determining gamma radiation effect on bond strength and nanoleakage of esthetic restorations in laser-prepared cavities. The null hypothesis established for this research is that there is no variation between the control and gamma-irradiated groups in terms of microshear bond strength and nanoleakage.

\section{MATERIALS AND METHODS}

The materials' name, composition, and manufacturer used in this study are presented in Table 1.

\section{Teeth selection and preparation of specimens}

Fifty-six freshly extracted human third molars, free of caries and cracks, were collected from 20 to 36 years old patients. They were randomly distributed among eight groups using an excel sheet. Teeth were cleaned with ultrasonic cleaner, stored in weekly changed distilled water, and used in 3 months.

\section{Microshear bond strength specimen's preparation}

Twenty-eight molars ( $n=7)$, except the buccal surface, were mounted in self-curing acrylic resin (Acrostone, Egypt). A high-speed superfine diamond bur was used to remove enamel from the buccal surfaces and to reveal flat dentin surfaces. ${ }^{[10]}$ The surfaces were checked by a magnifying lens to confirm complete removal of enamel and then polished according to Adebayo et al. in 2012. ${ }^{[11]} \mathrm{Er}, \mathrm{Cr}$ :YSGG laser was used in a focused mode to irradiate the dentin surfaces for $10 \mathrm{~s}$ (Biolase), ${ }^{[12]}$ with parameters of $4 \mathrm{~W}$ power, $20 \mathrm{~Hz}$ repetition rate, and 50/30\% air/water coolant. ${ }^{[13]}$

The prepared teeth were classified into four groups. In the first and second groups, application of Single Bond Universal Adhesive was performed according to the manufacturer's instructions and then light cured using Dr's Light LED light-curing unit RF America IDS $\left(1600 \mathrm{~mW} / \mathrm{cm}^{2}\right)$. A radiometer was used after curing every 10 specimens to ensure adequate curing intensity for all specimens. Before the bond light-curing, two vinyl Tygon tubes with diameter $\pm 0.8 \mathrm{~mm}$ and height $2 \mathrm{~mm}$ were sited on each dentin surface. The resin composite (Filtek Z350) was packed into the tubes using dental pluggers. Over it, a transparent matrix strip was positioned and light-cured for $20 \mathrm{~s}$ at zero distance. The mean microshear bond strength of each tooth was calculated from these two readings to get a total number of 28 mean values in $\mathrm{MPa}$.

In the third and fourth groups, Ketac Nano Primer was applied according to the manufacturer's instruction and then light cured. The nanoglass ionomer

\begin{tabular}{|c|c|c|}
\hline Material and trade name & Composition & Manufacturer \\
\hline $\begin{array}{l}\text { Nanocomposite (Filtek }{ }^{\mathrm{TM}} \\
\text { Z350) Shade A2 }\end{array}$ & $\begin{array}{l}\text { Bis-GMA, UDMA, TEGDMA, and Bis-EMA resins, nonagglomerated fillers } 4-11 \mathrm{~nm} \text { zirconia, } \\
20 \mathrm{~nm} \text { silica, and an aggregated zirconia/silica cluster fillers }(0.6-10 \mu) \text {. The filler loading is } \\
78.5 \% \text { by weight }\end{array}$ & $\begin{array}{l}\text { 3M ESPE, Dental } \\
\text { Products, St. } \\
\text { Paul, MN, USA }\end{array}$ \\
\hline $\begin{array}{l}\text { Self-etch adhesive (Single } \\
\text { Bond Universal) }\end{array}$ & HEMA, monomer MDP, Dimethacrylate resins, VBCP, filler, ethanol, water, initiators, and silane & \\
\hline $\begin{array}{l}\text { Nanoglass ionomer }\left(\text { Ketac }^{\mathrm{TM}}\right. \\
\text { N100) Shade A3 }\end{array}$ & $\begin{array}{l}\text { Polyalkenoic acid VBCP, HEMA, Deionized water, fluroaluminosilicate glass }(1 \mu) \text {, } \\
\text { surface-treated silica/zirconia nanofillers }(5-25 \mathrm{~nm}) \text {, and nanoclusters }(1-1.6 \mu) \text {. The filler } \\
\text { loading is } 69 \% \text { by weight }\end{array}$ & \\
\hline $\begin{array}{l}\text { Self-etch primer (Ketac } \\
\text { Nano Primer) }\end{array}$ & VitreBond ${ }^{\mathrm{TM}}$ copolymer, HEMA, water, and photoinitiator & \\
\hline Artificial saliva & $\begin{array}{l}\mathrm{Na}_{3} \mathrm{PO}_{4}-3.90 \mathrm{mM}, \mathrm{NaCl}_{2}-4.29 \mathrm{mM}, \mathrm{KCl}-17.98 \mathrm{mM}, \mathrm{CaCl}_{2}-1.10 \mathrm{mM}, \mathrm{MgCl}_{2}-0.08 \mathrm{mM} \text {, } \\
\mathrm{H}_{2} \mathrm{SO}_{4}-0.50 \mathrm{mM}, \mathrm{NaHCO}_{3}-3.27 \mathrm{mM} \text {, and distilled water. The pH was set at a level of 7. }{ }^{\left[{ }^{9}\right]}\end{array}$ & \\
\hline
\end{tabular}


(Ketac N100) was packed into the Tygon tubes and light cured for $20 \mathrm{~s}$.

\section{Application of gamma radiation}

The second and fourth groups were irradiated by fractionated gamma radiation at a dose of $60 \mathrm{~Gy}$, three times a week (day after day) for 1 week (20 Gy/ 3 fractions/week). ${ }^{[14]}$ The radiation was carried out using 137 Cesium Gamma Cell 40 at the Atomic Energy Authority, with a dose rate $0.708 \mathrm{rad} / \mathrm{sec}$ at the time of experiment. A solution of artificial saliva was used to store all groups for $24 \mathrm{~h}$.

\section{Microshear bond strength test assessment}

The specimens were fixed in an Instron Machine (Model 3345; Instron Universal Testing Machine, England Instruments, with a load cell of $5 \mathrm{KN}$, and data record was done using computer software BlueHill 3 Instron). An orthodontic wire loop (diameter $=0.14 \mathrm{~mm}$ ) was wrapped around the base of the bonded microcylinder assembly and aligned with the loading axis of the movable upper compartment of the machine. The force was loaded to failure, at a crosshead speed of $0.5 \mathrm{~mm} / \mathrm{min}$. Calculations of the microshear bond strength values were performed and expressed in $\mathrm{MPa}$. The obtained results did not include resin cylinders with premature failure.

\section{Nanoleakage specimen's preparation}

Class V cavities, with the dimensions according to Marotti et al. in 2010, were prepared in the buccal surfaces of the other 28 selected teeth. ${ }^{[15]}$ To standardize the cavity outline, a window with the selected width and length was cut on a stainless steel matrix band and the depth was measured by a periodontal probe. Hence, three readings were obtained from each cavity to get a total number of 84 readings from all the teeth, and the mean nanoleakage value was obtained for each tooth. At the cervical third of the teeth, all cavities were prepared, $2 \mathrm{~mm}$ occlusal to the cementoenamel junction using Er, Cr:YSGG laser with parameters $6 \mathrm{~W}$ in enamel and $4 \mathrm{~W}$ in dentin. ${ }^{[16]}$ The nanocomposite was packed in a bulk using a plastic instrument. Ketac Nano Primer was applied and the nanoglass ionomer was packed and light cured as in the case of microshear bond strength specimens. Half of the specimens were exposed to gamma radiation and stored as previously mentioned.

Sticky wax was used to seal the root apices and two layers of nail varnish were used to coat the entire tooth, except for $1 \mathrm{~mm}$ apart from the margins of the restoration. ${ }^{[17]}$ Then, the specimens were submerged in a solution of $50 \%$ ammoniacal silver nitrate ( $\mathrm{pH}$ 9.5) for $24 \mathrm{~h}$ in a dark chamber. ${ }^{[18]}$ Teeth were then thoroughly rinsed in distilled water and immersed in a photodeveloping solution for $8 \mathrm{~h}$ under a fluorescent light. ${ }^{[19]}$

\section{Nanoleakage test assessment}

The selected specimens were divided buccolingually across the restoration center with a diamond saw in a cutting machine (IsoMet 4000; Buehler, Lake Bluff, IL, USA), under a water coolant. They were polished using a graded series of Soflex discs (3M Co.) in the descending order from the course to fine one and then ultrasonically cleaned to remove the smear layer. Finally, one section of each preparation was examined by a X-ray microanalyzer (Module Oxford 6587 INCA X-sight) attached to JEOL JM-5500 LV scanning electron microscopy using high vacuum mode at $20 \mathrm{KV}$. Electron dispersive analytical X-ray (EDAX) analysis was also performed to identify the presence of metallic silver particles. Three points at the interfaces between the teeth and the restorations (occlusal and gingival) were selected for scanning and EDAX quantification. The mean percentage of the silver ion deposition was calculated. ${ }^{[20]}$

\section{Statistical analysis}

Data were collected and analyzed using IBM SPSS Statistics for Windows, Version 23.0 (Armonk, NY: IBM Corp., USA). All normally distributed continuous data are presented. Two-way ANOVA was done to examine the main effects and interactions relating to types of filling and tested groups on microshear bond strength $(\mathrm{MPa})$ or nanoleakage (Ag \%), respectively. Independent sample $t$-test was used to examine if there were any differences found between groups.

\section{RESULTS}

Microshear bond strength values are presented in Table 2 and Figure 1.

\begin{tabular}{|c|c|c|c|c|c|}
\hline & \multicolumn{2}{|c|}{ Nanocomposite } & \multicolumn{2}{|c|}{$\begin{array}{c}\text { Nanoglass } \\
\text { ionomer }\end{array}$} & \multirow[t]{2}{*}{$P$} \\
\hline & Mean & SD & Mean & SD & \\
\hline Control group & 11.7 & 1.8 & 0.86 & 0.074 & $0.0001^{* * *}$ \\
\hline $\begin{array}{l}\text { Gamma-radiated } \\
\text { group }\end{array}$ & 12.5 & 1.04 & 0.37 & 0.059 & $0.0001^{* * *}$ \\
\hline$P$ & \multicolumn{2}{|c|}{0.197 (NS) } & \multicolumn{2}{|c|}{$0.0001^{* * *}$} & \\
\hline
\end{tabular}


Nanoleakage values are shown in Table 3 and Figure 2.

Representative photomicrographs were taken at magnification ranges from $\times 200$ to $\times 300$, as presented in Figures 3-6. For the nanocomposite groups, either control or gamma irradiated, the gap size corresponds to the low $\mathrm{Ag} \%$ as shown in Figures 3 and 4. However, both the nanoglass ionomer groups revealed wider gap size that corresponds to the higher $\mathrm{Ag} \%$ in relation to the nanocomposite groups as shown in Figures 5 and 6.

\section{DISCUSSION}

In the minimally invasive dentistry field, Er, Cr:YSGG laser was approved to be an effective and conservative tool. Among its numerous advantages, it induces less vibration and noise, preserves more tooth structure, eliminates the need for anesthesia, and has an antibacterial effect. ${ }^{[3]}$ As the restorative procedures are extremely stressful for patients

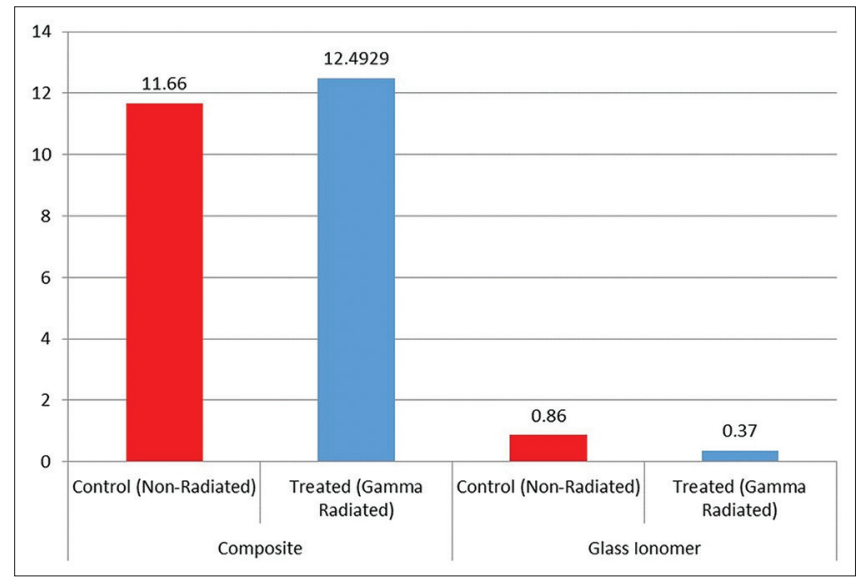

Figure 1: Column chart of microshear bond strength mean values for the tested groups

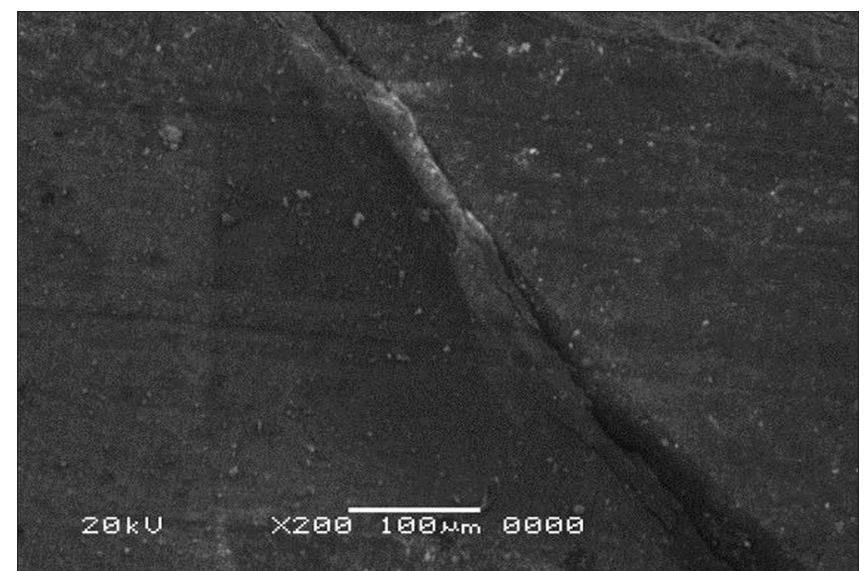

Figure 3: Images of tooth-restoration interface for the nanocomposite control group receiving head and neck radiotherapy, laser became the most beneficial tool for the treatment of such patients who seek for a comfortable and painless procedure while restoring their teeth. ${ }^{[21]}$ Bonded restorations tend to be the most efficient methods to restore irradiated teeth. However, by literature reviewing, many controversies were revealed regarding the success of such restorations.

In the current study, microshear bond strength showed significant higher bond strength values of

\begin{tabular}{|c|c|c|c|c|c|}
\hline & \multicolumn{2}{|c|}{ Nanocomposite } & \multicolumn{2}{|c|}{$\begin{array}{c}\text { Nanoglass } \\
\text { ionomer }\end{array}$} & \multirow[t]{2}{*}{$P$} \\
\hline & Mean & SD & Mean & SD & \\
\hline Control group & 1.18 & 0.63 & 2.32 & 0.35 & $0.001^{* *}$ \\
\hline $\begin{array}{l}\text { Gamma-radiated } \\
\text { group }\end{array}$ & 0.9 & 0.43 & 2.07 & 0.28 & $0.0001^{* * *}$ \\
\hline$P$ & \multicolumn{2}{|c|}{0.355 (NS) } & \multicolumn{2}{|c|}{0.168 (NS) } & \\
\hline
\end{tabular}

**, ${ }^{* *}$ Significant at $P \leq 0.05$. NS: Not significant, SD: Standard deviation

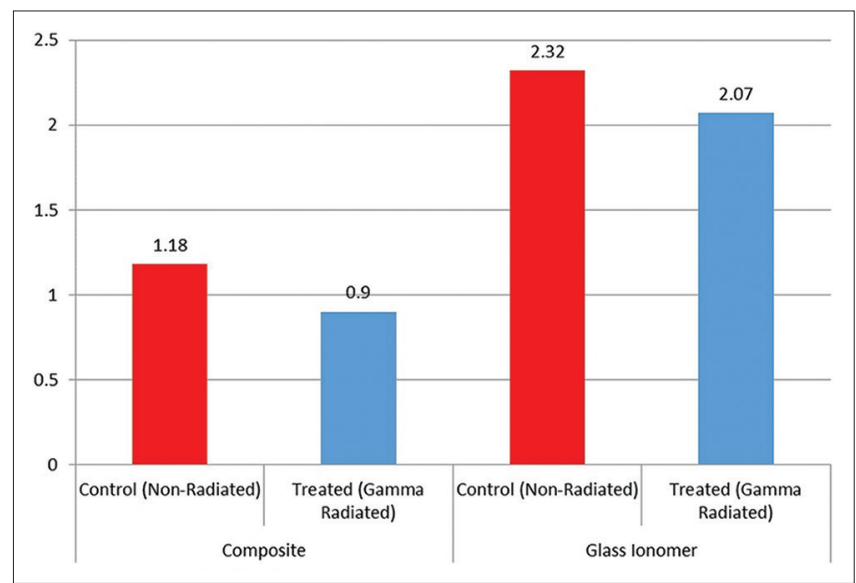

Figure 2: A column chart of nanoleakage mean values for the tested groups

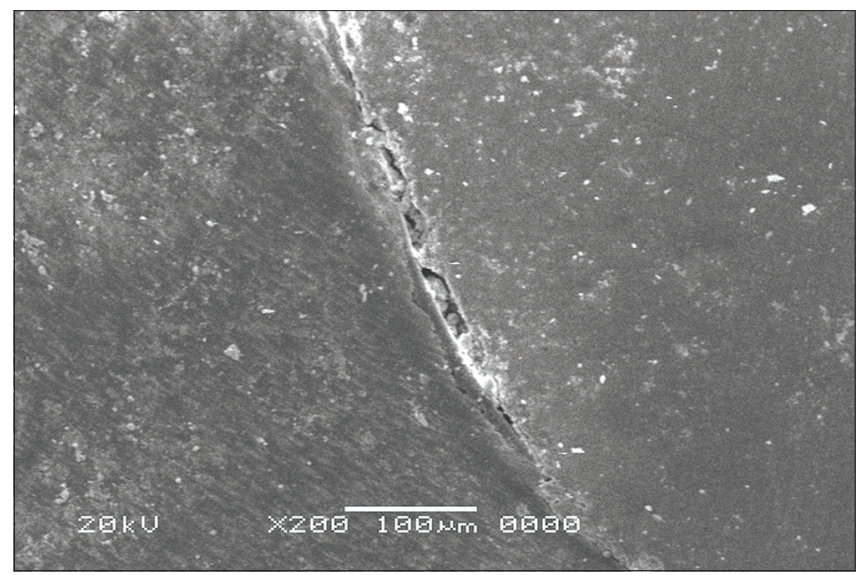

Figure 4: Images of tooth-restoration interface for the nanocomposite gamma-radiated group 


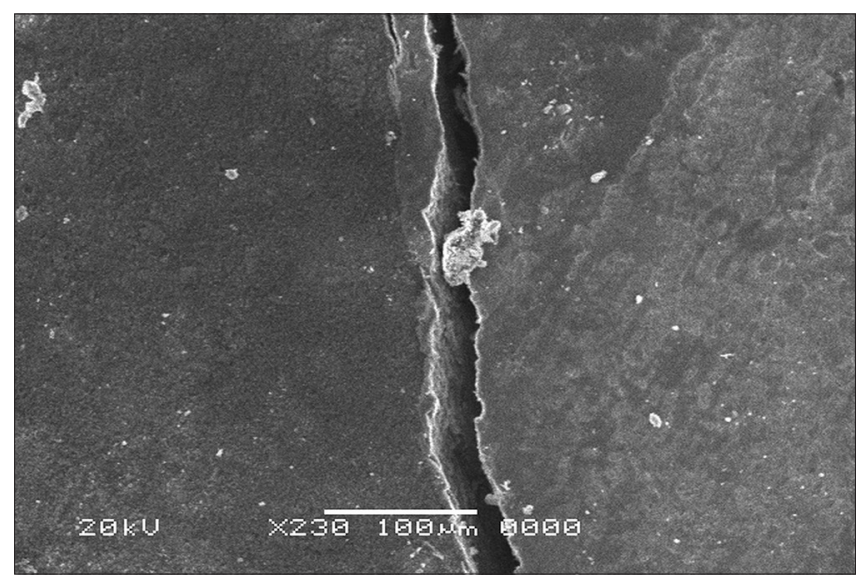

Figure 5: Images of tooth-restoration interface for the nanoglass ionomer control group

the nanocomposite than those of nanoglass ionomer [Table 2 and Figure 1]. This could be referred to the self-etching adhesives used with nanocomposite that allows resin penetration into the dentinal tubules and infiltration to the underlying demineralized dentin forming a hybrid layer. Another factor that enhances wetting of dentin is the hydrophilicity of HEMA adhesive group. ${ }^{[22]}$ Application of nanoglass ionomer following the primer, without any intermediary bonding material, lowers the values of microshear bond strength. ${ }^{[23]}$ Moreover, the increased viscosity of glass ionomer restorations decreases the penetration of the material through the full depth of the available irregularities of the prepared surfaces. ${ }^{[2]}$

In this study, the results revealed insignificant increase in the values of the bond strength for the investigated nanocomposite after gamma radiation. This was in relative agreement with Seif et al. in $2013,{ }^{[14]}$ who reported an increase in the bond strength of nanocomposite significantly after gamma radiation due to the continued polymerization arising from the incident gamma radiation beam increasing the degree of polymerization. The nanoglass ionomer-restored specimens showed extremely statistical significant decrease in the microshear bond strength values after gamma radiation. That was in accordance with Yesilyurt et al. in 2008, who stated that the setting reaction of glass ionomer and its bonding to dentin was directly affected by irradiation. ${ }^{[25]}$

Table 3 and Figures 2-6 show that none of the tested restorative materials completely eliminated nanoleakage due to the high C-factor of Class V cavities, which accentuate the effect of the polymerization shrinkage stresses. This was supported by Price et al. in 2003, who found that pathways become available for

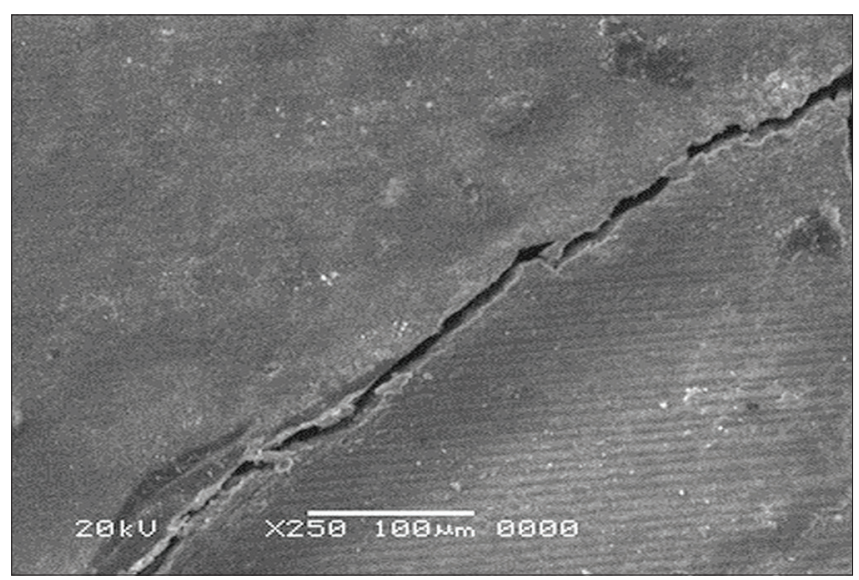

Figure 6: Images of tooth-restoration interface for the nanoglass ionomer gamma-radiated group

dye penetration in cavities with high C-factor which decreased the bond strength. ${ }^{[26]}$

Our study showed high significant increase in nanoleakage of nanoglass ionomer restorations than nanocomposite restorations in both groups due to the micromechanical bonding in the nanocomposite-restored cavities. Furthermore, mild self-etch adhesives, which are less sensitive to moisture, have characteristic property that lies in incomplete elimination of hydroxyapatite from the interaction zone which protects the collagen against hydrolysis, as well the available calcium has a chemical interaction with specific adhesive monomers which provide stronger adhesion. ${ }^{[27]}$

Toledano et al. in 2003 reported that nanoglass ionomer had higher penetration due to its great susceptibility to water sorption and solubility than resin composite. ${ }^{[28]}$ The bonding mechanism of nanoglass ionomer depends mainly on chemical bonding rather than micromechanical bonding, which is an important factor in resisting polymerization shrinkage stresses in high C-factor cavities Class V cavities. ${ }^{[29]}$

Our results showed nonsignificant decrease of the nanoleakage values in the gamma-irradiated groups in both nanocomposite and nanoglass ionomer restorations than the control group. This was in harmony with Bulucu et al. in 2009[30] and Seif et al. in 2013, ${ }^{[14]}$ who stated that irradiation did not influence the microleakage in Class V cavities.

In this study, there is no relationship between the bond strength results and the nanoleakage values because the cavity margins were totally located 
in dentin in the bond strength test. However, in nanoleakage test, the margins were located in enamel leading to difference in the polymerization shrinkage stresses. ${ }^{[31]}$ The null hypothesis for this study was partially accepted.

\section{CONCLUSION}

1. Therapeutic dose of gamma radiation has minimal effect on the microshear bond strength and nanoleakage of nanocomposite

2. The microshear bond strength of nanoglass ionomer is adversely affected by gamma radiation while nanoleakage is not affected

3. Nanocomposite is more suitable as a restorative material for cancer patients than nanoglass ionomer.

\section{Financial support and sponsorship Nil.}

\section{Conflicts of interest}

There are no conflicts of interest.

\section{REFERENCES}

1. Kielbassa AM, Hinkelbein W, Hellwig E, Meyer-Lückel H. Radiation-related damage to dentition. Lancet Oncol 2006;7:326-35.

2. Rosa RS, Balbinot CE, Blando E, Mota EG, Oshima HM, Hirakata L, et al. Evaluation of mechanical properties on three nanofilled composites. Stomatologija 2012;14:126-30.

3. Fernanda SS, Andréa DN, Sérgio BB, Cynthia S, Narciso GN, Bona MA. A comparative leakage study on Er, Cr:YSGG laser- and bur-prepared class $\mathrm{V}$ cavities restored with a low-shrinkage composite using different filling techniques. Braz J Oral Sci 2013;12:119-24.

4. Yazici AR, Yıldırım Z, Antonson SA, Kilinc E, Koch D, Antonson DE, et al. Comparison of the Er, Cr:YSGG laser with a chemical vapour deposition bur and conventional techniques for cavity preparation: A microleakage study. Lasers Med Sci 2012;27:23-9.

5. Van Meerbeek B, Peumans M, Poitevin A, Mine A, Van Ende A, Neves A, et al. Relationship between bond-strength tests and clinical outcomes. Dent Mater 2010;26:e100-21.

6. Duarte Pde B, da Silva EM. Nanoleakage phenomenon on deproteinized human dentin. J Appl Oral Sci 2007;15:285-91.

7. Baygin O, Korkmaz FM, Tüzüner T, Tanriver M. The effect of different enamel surface treatments on the microleakage of fissure sealants. Lasers Med Sci 2012;27:153-60.

8. Shahabi S, Ebrahimpour L, Walsh LJ. Microleakage of composite resin restorations in cervical cavities prepared by Er, Cr:YSGG laser radiation. Aust Dent J 2008;53:172-5.

9. Lata S, Varghese NO, Varughese JM. Remineralization potential of fluoride and amorphous calcium phosphate-casein phospho peptide on enamel lesions: An in vitro comparative evaluation. J Conserv Dent 2010;13:42-6

10. Weerasinghe DS, Nikaido T, Wettasinghe KA, Abayakoon JB,
Tagami J. Micro-shear bond strength and morphological analysis of a self-etching primer adhesive system to fluorosed enamel. J Dent 2005;33:419-26.

11. Adebayo OA, Burrow MF, Tyas MJ, Palamara J. Effect of tooth surface preparation on the bonding of self-etching primer adhesives. Oper Dent 2012;37:137-49.

12. Ferreira LS, Apel C, Francci C, Simoes A, Eduardo CP, Gutknecht N, et al. Influence of etching time on bond strength in dentin irradiated with erbium lasers. Lasers Med Sci 2010;25:849-54.

13. Korkmaz FM, Baygin O, Tuzuner T, Bagis B, Arslan I. The effect of an erbium, chromium:Yttrium-scandium-gallium-garnet laser on the microleakage and bond strength of silorane and micro-hybrid composite restorations. Eur J Dent 2013;7:S33-40.

14. Seif MB, Habib NA, Aboutabl Z, El Maghraby EM. The Effect of Gamma Radiation on the Bond Strength and Microleakage of Two Aesthetic Restorative Materials. Master Thesis, Cairo University; 2013. p. 68-79.

15. Marotti J, Geraldo-Martins VR, Bello-Silva MS, de Paula Eduardo C, Apel C, Gutknecht N, et al. Influence of etching with erbium, chromium:yttrium-scandium-gallium-garnet laser on microleakage of class V restoration. Lasers Med Sci 2010;25:325-9.

16. Öznurhan F, Ölmez A. Nanoleakage in primary teeth prepared by laser irradiation or bur. Lasers Med Sci 2013;28:1099-105.

17. El Naga AA, Youssef MK. Effect of different bleaching methods and storage periods on nanoleakage. J Am Sci 2015;11:71-7.

18. Tay FR, Pashley DH, Yoshiyama M. Two modes of nanoleakage expression in single-step adhesives. J Dent Res 2002;81:472-6.

19. Bedran-de-Castro AK, Pereira PN, Pimenta LA, Thompson JY. Effect of thermal and mechanical load cycling on nanoleakage of class II restorations. J Adhes Dent 2004;6:221-6.

20. El Naga AA. Nanoleakage of giomer resin bonded with either total- or self-etch adhesives. J Am Sci 2012;8:27-34

21. Fuller CD, Diaz I, Cavanaugh SX, Eng TY. In vivo dose perturbation effects of metallic dental alloys during head and neck irradiation with intensity modulated radiation therapy. Oral Oncol 2004;40:645-8.

22. Roulet JF, Degrange M. Adhesion, The Silent Revolution in Dentistry. $1^{\text {st }}$ ed. USA: Quint Publishing CO, Inc.; 2000.

23. Korkmaz Y, Gurgan S, Firat E, Nathanson D. Shear bond strength of three different nano-restorative materials to dentin. Oper Dent 2010;35:50-7.

24. Davidson CL, Major IA. Advances in Glass Ionomer Cements. USA Quintessence Publishing Company, Incorporation; 1999. p. 18-43.

25. Yesilyurt C, Bulucu B, Sezen O, Bulut G, Celik D. Bond strengths of two conventional glass-ionomer cements to irradiated and non-irradiated dentin. Dent Mater J 2008;27:695-701.

26. Price RB, Dérand T, Andreou P, Murphy D. The effect of two configuration factors, time, and thermal cycling on resin to dentin bond strengths. Biomaterials 2003;24:1013-21.

27. Chersoni S, Suppa P, Grandini S, Goracci C, Monticelli F, Yiu C, et al. In vivo and in vitro permeability of one-step self-etch adhesives. J Dent Res 2004;83:459-64.

28. Toledano M, Osorio R, Osorio E, Fuentes V, Prati C, Garcia-Godoy F, et al. Sorption and solubility of resin-based restorative dental materials. J Dent 2003;31:43-50.

29. Coutinho E, Cardoso MV, De Munck J, Neves AA, Van Landuyt KL, Poitevin A, et al. Bonding effectiveness and interfacial characterization of a nano-filled resin-modified glass-ionomer. Dent Mater 2009;25:1347-57.

30. Bulucu B, Avsar A, Demiryürek EO, Yesilyurt C. Effect of radiotherapy on the microleakage of adhesive systems. J Adhes Dent 2009;11:305-9.

31. Kenshima S, Reis A, Uceda-Gomez N, Tancredo Lde L, Filho LE, Nogueira FN, et al. Effect of smear layer thickness and $\mathrm{pH}$ of self-etching adhesive systems on the bond strength and gap formation to dentin. J Adhes Dent 2005;7:117-26. 